\title{
ARC SPECTRUM OF SILICON IN THE RED AND INFRARED
}

By C. C. Kiess

ABSTRACT

No accurate description of the red and infrared portion of the are spectrum of silicon has been published in the 40 years that have elapsed since Rowland's work which terminated at 5,948 A. In this paper, wave lengths are given for 130 new lines between 6,125 and 11,290 A, many of which are present in the solar spectrum, including the strongest hitherto unidentified Fraunhofer line. More than 50 percent of these lines have been classified as combinations between new terms and terms already established for Si I. The new terms arise from the electron configurations containing the $4 p, 4 f$, and $5 f$ electrons.

\section{CONTENTS}

Page

775

776

777

\section{INTRODUCTION}

Several years ago Fowler ${ }^{1}$ published an analysis of the arc spectrum of silicon that made use of all the wave-length data then available and gave additional wave lengths down to $1590 \mathrm{~A}$ in the extreme ultraviolet. From this work, which gave the salient features of the term structure of Si I, it appears that no extension of our knowledge of the spectrum has been made into the red and infrared beyond the longest wave length, 5,948.5 A observed by Rowland 40 years ago. ${ }^{2}$ However, Fowler's analysis indicated that several groups of prominent lines were to be expected in this region. It is true that McLennan and Shaver ${ }^{3}$ published a list of red and infrared lines purporting to be characteristic of the arc spectrum of silicon, but none of them, except possibly three, appear to belong to this element.

Exploration of the arc spectrum of silicon into the red and infrared, as far as photographic methods would permit, was begun more than 17 years ago at the Bureau of Standards. The material used as electrodes in the arc was fused silicon, about 90 percent pure, in the form of rough lumps. However, this material emitted the spectra of iron, titanium, vanadium, zirconium, calcium, barium, and other impurities, with such prominence that only a few of the remaining unidentified lines could, with certainty, be ascribed to silicon. These were identified with solar absorption lines by Meggers ${ }^{4}$ in his extension of the sun's spectrum to 9,000 A.

\footnotetext{
1 Proc. Roy. Soc. (London), vol. A, 123, p. 422, 1929.

2 Phil. Mag., Series 5, vol. 36, p. 49, 1893.

3 Trans. Roy. Soc. (Canada), series III, vol. 18, p. 21, 1924.

- Publ. Allegheny Observatory, vol. 6, p. 13, 1919.
} 
In the meantime, our knowledge of spectra in the red and near infrared has increased to such a state of completeness that it is now possible to eliminate from an unknown spectrum the lines due to the metallic impurities in the source. Furthermore, with a fairly complete term analysis of a spectrum, such as Fowler has made for Si I, it is possible to test new lines for their relationship with it.

The discovery, about 2 years ago, at the Eastman Kodak Laboratories, of new photo-sensitizing materials that have greatly extended the range and increased the speed of plates suitable for infrared photography, has made it desirable to examine again the spectrum emitted by silicon in this region. The properties of these new sensitizers, named mesocyanin and xenocyanin, have been described by Mees. ${ }^{5}$ They have their maximum sensitizing power at 8,600 and $9,700 \mathrm{~A}$, respectively, but xenocyanin is effective throughout a broad band extending from 9,000 to nearly $12,000 \mathrm{~A}$.

\section{APPARATUS AND METHODS}

The observations were made with two grating spectrographs equipped with 21 -foot concave gratings, ruled with 7,500 and 20,000 lines per inch, and a plane grating ruled with 20,000 lines per inch. The three instruments give dispersions in the first order spectrum of $10.4,3.5$, and $2.7 \mathrm{~A} / \mathrm{mm}$, respectively. For wave lengths longer than $9,000 \mathrm{~A}$ only the spectrograph with the small dispersion was used; for wave lengths shorter than 9,000 A all three instruments were used. In every case, exposures to the silicon arc were accompanied by exposures to the iron arc to furnish standard wave lengths in either the first or second order for use in the wave length determinations.

The light source was the arc in air between lumps of the same fused silicon as was used in the work of 17 years ago. The arcs carried currents ranging from 6 to 16 amperes supplied by 220 -volt dc mains. It was found that, with lumps of silicon weighing $10 \mathrm{~g}$ or less and with currents under 10 amperes, it was necessary to restrike the arc every minute or two. With heavier lumps, $50 \mathrm{~g}$ or more in weight, the arcs burned steadily for periods up to one half or three fourths hour. Craters of glassy silica formed over the surface of the electrodes so that when the arc went out, it could not be struck again until the glaze was broken off.

As stated above, all the recent observations have been made on the new types of plates produced by the Eastman Kodak Laboratories. Before exposure, the plates were hypersensitized in an ammonia bath, then rinsed in alcohol, and dried rapidly in a current of air. To record the silicon arc spectrum as tabulated below, exposure times ranging from 1 to 4 hours were required. The plates were measured and reduced according to our usual practice, the reference lines of the iron arc being those adopted as secondary standards by the International Astronomical Union. ${ }^{6}$ No measurements of the lines between 3,905 and 5,948 A appear to have been made on the international wave-length scale since those of Fowler, ${ }^{7}$ who

s J. Optical Soc. Am., vol. 21, p. 753, 1931; vol. 22, p. 204, 1932; vol. 23, p. 229, 1933.

8 Trans. Internat. Astron. Union, vol. 3, p. 77, 1928.

7 Phil. Trans. Roy. Soc. (London), vol. A 225, p. 1, 1925. 
reported three new lines in the yellow. These lines have been remeasured on the high-dispersion plates made in this investigation and the results, incorporated in table 1, are described below.

\section{RESULTS}

The new wave lengths of the silicon arc spectrum are given in table 1. Most of the lines are not sharp and some are asymmetrical, being shaded toward the red or the violet. These qualities are indicated in the second column of the table by the letters, $h, l$, and $v$, respectively, following the intensity. The letter $b$ indicates a broadening of the line, which, however, is not sufficient to impart the appearance of diffuseness. All the other lines are sharp.

Comparison of the wave lengths of table 1 with the solar lines in the Revision of Rowland's Preliminary Table ${ }^{8}$ and with Babcock's list of Temporary Standards in the Infrared Solar Spectrum ${ }^{9}$ shows that all the intense silicon lines, and many of the fainter ones, are in the sun's spectrum. These include the line at 6,155 A, the strongest hitherto unidentified solar line. In general, the laboratory wave lengths are longer than the solar values. For the lines in the yellow, which are relatively sharp and can be measured more accurately than the diffuse and unsymmetrical red lines, the mean shift is $+0.04 \mathrm{~A}$. For the red lines it is $+0.12 \mathrm{~A}$. Part of these shifts may be the result of pressure and probably Stark effects in the source, the arc in air; but in the case of the red lines the measurements are affected in many instances by blending of strong multiplet lines with very close and fainter satellites. The wave lengths of the infrared lines beyond $10,000 \mathrm{~A}$ are systematically shorter than the solar lines by $0.06 \mathrm{~A}$. These lines were measured only on plates taken with the low-dispersion grating and the difference between their wave lengths and the solar values may be accounted for by difference in scale between the two sets of measurements.

\section{TABLE 1.-Wave lengths in the arc spectrum of silicon}

Note.-The angstrom. In view of the present unanimous agreement and general practice in expressing optical wave lengths in terms of the so-called "international angstrom" the Bureau of Standards considers the time opportune to represent the international angstrom by the abbreviation $A$. Where the Rowland scale of wave lengths is intended it should be clearly specified as such.

The "angstrom" as at present used was defined and adopted in 1907 by the International Union for Cooperation in Solar Research (now the International Astronomical Union) and also adopted in 1928 by the International Conference on Weights and Measures. The angstrom is equal to $1 / 6438.4696$ of the wave length of cadmium red radiation, and within the limits of the most refined measurements of Michelson, and of Fabry, Perot, and Benoit, this value of the angstrom is identical with the definition 1 angstrom $=10^{-10}$ meter.

8 Carnegie Institution of Washington, Publication no. 396, 1928.

0 Trans. Internat. Astron. Union, vol. 4, p. 83, 1932. 


\begin{tabular}{|c|c|c|c|}
\hline$\lambda_{\text {sir }} \mathrm{A}$ & Intensity & $\nu_{\nabla \mathrm{aO}} \mathrm{cm}^{-1}$ & Term combinations \\
\hline $11,290.02$ & 0 & $8,854.95$ & \\
\hline $11,187.75$ & 1 & $8,935.90$ & \\
\hline $11,018.02$ & 7 & $9,073.59$ & $4 s^{3} \mathrm{P}_{2}^{\circ}-4 p^{3} \mathrm{D}_{2}$ \\
\hline $10,982.40$ & 1 & $9,102.98$ & \\
\hline $10,979.27$ & 10 & $9,105.60$ & $4 s^{3} \mathrm{P}_{2}^{\circ}-4 p^{3} \mathrm{P}_{1}$ \\
\hline $\begin{array}{l}10,885.23 \\
10,882,58\end{array}$ & $2 b$ & $\begin{array}{l}9,184.25 \\
9,186.48\end{array}$ & \\
\hline $\begin{array}{l}10,882.58 \\
10,869.50\end{array}$ & $\begin{array}{l}16 \\
50\end{array}$ & $\begin{array}{l}9,180.48 \\
9,197.54\end{array}$ & $4 s^{1} \mathrm{P}_{\mathrm{j}}-4 p^{1} \mathrm{D}_{2}$ \\
\hline $10,843.98$ & $15 b$ & $9,219.19$ & $4 s^{3} \mathrm{P}_{1}-4 p^{3} \mathrm{P}_{0}$ \\
\hline $10,827.06$ & 50 & $9,233.59$ & $4 s^{3} \mathrm{P}_{2}^{\circ}-4 p^{3} \mathrm{P}_{2}$ \\
\hline $10,786.81$ & 25 & $9,268.05$ & $4 s^{3} \mathrm{P}_{1}^{\circ}-4 p^{3} \mathrm{D}_{2}$ \\
\hline $10,784.02$ & 2 & $9,270.44$ & \\
\hline $10,749.32$ & 35 & $9,300.36$ & $4 s^{3} \mathrm{P}_{1}-4 p^{3} \mathrm{P}_{1}$ \\
\hline $10,727.17$ & $30 b$ & $9,319.57$ & $4 s^{3} \mathrm{P}_{2}^{2}-4 p^{3} \mathrm{D}_{3}$ \\
\hline $10,694.14$ & $25 b$ & $9,348.35$ & $4 s^{1} \mathrm{P}_{1}-4 p^{1} \mathrm{P}_{1}$ \\
\hline $10,689.56$ & $20 b$ & $9,352.36$ & $4 s^{3} \mathrm{P}_{0}^{0}-4 p^{3} \mathrm{D}_{1}$ \\
\hline $10,660.94$ & 40 & $9,377.47$ & $4 s^{3} \mathrm{P}_{0}^{\circ}-4 p^{3} \mathrm{P}_{1}$ \\
\hline $10,627.76$ & $15 b$ & $9,406.74$ & \\
\hline $10,603.37$ & 50 & $9,428.39$ & $4 s^{3} \mathrm{P}_{1}-4 p^{3} \mathrm{P}_{2}$ \\
\hline $10,585.08$ & 100 & $9,444.67$ & $4 s^{3} \mathrm{P}_{2}^{0}-4 p^{3} \mathrm{~S}_{1}$ \\
\hline $10,499.00$ & 2 & $9,522.10$ & \\
\hline $10,371.25$ & 50 & $9,639.40$ & $4 s^{3} \mathrm{P}_{1}^{\circ}-4 p^{3} \mathrm{~S}_{1}$ \\
\hline $10,288.93$ & 25 & $9,716.52$ & $4 s^{3} \mathrm{P}_{0}^{0}-4 p^{3} \mathrm{~S}_{1}$ \\
\hline $10,155.88$ & 1 & $9,843.81$ & $4 p^{3} \mathrm{D}_{3}-5 d^{3} \mathrm{D}_{3}^{\circ}$ \\
\hline $10,100.84$ & 1 & $9,897.45$ & \\
\hline $10,067.74$ & 3 & 9, 929. 99 & $4 p^{3} \mathrm{P}_{2}-5 d^{3} \mathrm{D}_{3}^{\circ}$ \\
\hline $10,020.16$ & 1 & $9,977.15$ & $3 d^{1} \mathrm{D}_{2}^{\circ}-5 p^{3} \mathrm{P}_{1}$ \\
\hline $10,015.33$ & 1 & $9,981.96$ & \\
\hline $10,009.82$ & 1 & $9,987.45$ & \\
\hline $9,967.46$ & 1 & $10,029.90$ & \\
\hline $9,913.05$ & 1 & $10,084.95$ & $4 p^{3} \mathrm{P}_{2}-6 s^{3} \mathrm{P}_{1}^{\circ}$ \\
\hline $9,891.92$ & $5 b$ & $10,106.49$ & $4 p^{3} \mathrm{~S}_{1}-6 s^{3} \mathrm{P}_{2}^{\circ}$ \\
\hline $9,886.82$ & $2 b$ & $10,111.71$ & \\
\hline $9,839.40$ & $2 b$ & $10,160.44$ & $4 p^{3} \mathrm{P}_{1}-6 s^{3} \mathrm{P}_{1}$ \\
\hline $9,789.16$ & $2 h$ & $10,212.58$ & $4 p^{3} \mathrm{P}_{1}-6 s \mathrm{P}_{1}^{\circ}$ \\
\hline $9,770.10$ & $4 b$ & $10,232.51$ & $4 p^{3} \mathrm{D}_{3}-6 s^{3} \mathrm{P}_{2}^{\circ}$ \\
\hline $9,768.20$ & $5 b$ & $10,234.51$ & $4 s^{3} \mathrm{P}_{2}^{\circ}-4 p^{1} \mathrm{D}_{2}^{-}$ \\
\hline $9,757.84$ & $2 h$ & $10,245.36$ & $4 p^{3} \mathrm{D}_{2}-6 s^{3} \mathrm{P}_{0}^{0}$ \\
\hline $9,738.48$ & $6 b$ & $10,265.73$ & $4 p^{1} \mathrm{~S}_{n}-7 s^{1} \mathrm{P}_{1}^{0}$ \\
\hline $9,689.38$ & $8 b$ & $10,317.75$ & $4 p^{3} \mathrm{P}_{2}-6 s^{3} \mathrm{P}_{2}^{o}$ \\
\hline $9,627.00$ & 1 & $10,384.61$ & $4 s^{3} \mathrm{P}_{2}^{\circ}-4 p^{1} \mathrm{P}_{1}$ \\
\hline $9,585.80$ & 2 & $10,429.24$ & $4 s^{3} \mathrm{P}_{1}^{\circ}-4 p^{1} \mathrm{D}_{2}$ \\
\hline $9,505.25$ & 2 & $10,517.69$ & \\
\hline $9,413.54$ & 100 & $10,620.08$ & $4 s^{1} \mathrm{P}_{1}^{\circ}-4 p^{1} \mathrm{~S}_{0}$ \\
\hline $9,318.35$ & 3 & $10,728.57$ & \\
\hline $9,254.62$ & $4 h$ & $10,802.47$ & $3 d^{3} \mathrm{P}_{2}^{\circ}-5 f^{3} \mathrm{~F}_{3}$ \\
\hline $9,238.87$ & $2 h$ & $10,820.86$ & \\
\hline $9,208.70$ & $7 b$ & $10,856.32$ & \\
\hline $\begin{array}{l}9,022.38 \\
9,008.90\end{array}$ & $\begin{array}{l}2 h \\
5 h, l\end{array}$ & $\begin{array}{l}11,080.50 \\
11,097.09\end{array}$ & $3 d^{3} \mathrm{P}_{2}^{\circ}-5 f \mathrm{X}_{2}$ \\
\hline $8,949.34$ & $15 b$ & $11,170.95$ & \\
\hline $8,925.52$ & $8 b$ & $11,200.76$ & \\
\hline $8,899.50$ & $3 b$ & $11,233.51$ & \\
\hline $8,898.97$ & $3 b$ & $11,234.18$ & \\
\hline $8,892.96$ & $25 b$ & $11,241.77$ & \\
\hline $8,883.87$ & $4 b$ & $11,253.27$ & \\
\hline $8,791.28$ & $\begin{array}{l}5 b \\
4 b\end{array}$ & $\begin{array}{l}11,371.79 \\
11,372.30\end{array}$ & \\
\hline $\begin{array}{l}8,790.88 \\
8,790.53\end{array}$ & $\begin{array}{l}4 b \\
6 b\end{array}$ & $\begin{array}{l}11,372.30 \\
11,372.76\end{array}$ & \\
\hline $8,752.16$ & 200 & $11,422.62$ & $3 d^{1} \mathrm{D}_{2}^{\circ}-4 f^{3} \mathrm{~F}_{2}$ \\
\hline $8,742.57$ & 100 & $11,435.15$ & $3 d^{1} \mathrm{D}_{2}^{\circ}-4 f^{3} \mathrm{~F}_{3}^{\prime}$ \\
\hline $8,728.98$ & $5 b$ & $11,452.95$ & \\
\hline
\end{tabular}




\begin{tabular}{|c|c|c|c|}
\hline$\lambda_{B \text { ir }} \mathrm{A}$ & Intensity & $\nu_{\mathrm{vac}} \mathrm{cm}^{-1}$ & Term combinations \\
\hline $8,728.36$ & $10 b$ & $11,453.76$ & \\
\hline $8,648.54$ & $100 h, l$ & $11,559.47$ & \\
\hline $8,597.15$ & $2 h, l$ & $11,628.57$ & \\
\hline $8,556.63$ & $100 h$ & $11,683.64$ & $3 d^{1} \mathrm{D}_{2}-4 f^{3} \mathrm{D}_{2}$ \\
\hline $8,555.52$ & $2 h$ & $1 i, 685.15$ & $3 d^{1} \mathrm{D}_{2}-4 f^{3} \mathrm{D}_{3}$ \\
\hline $\begin{array}{l}8,536.45 \\
8,503.13\end{array}$ & $\begin{array}{l}3 b \\
1 b\end{array}$ & $\begin{array}{l}11,711.26 \\
11,757.15\end{array}$ & \\
\hline $8,502.33$ & $10 b$ & $11,758.25$ & $3 d^{1} \mathrm{D}_{2}^{\circ}-4 f \mathrm{X}_{3}$ \\
\hline $8,501.48$ & $3 b$ & $11,759.43$ & $3 d^{1} \mathrm{D}_{2}-4 f^{3} \mathrm{D}_{1}$ \\
\hline $8,444.01$ & $5 b$ & $11,839.46$ & $3 d^{1} \mathrm{D}_{2}-4 f \mathrm{X}_{2}$ \\
\hline $8,230.64$ & 7 & $12,146.39$ & $3 d^{3} \mathrm{D}_{3}^{\circ}-5 p^{3} \mathrm{P}_{2}$ \\
\hline $8,211.38$ & 2 & $12,174.88$ & $3 d^{3} \mathrm{D}_{2}-5 p^{3} \mathrm{P}_{2}$ \\
\hline $8,093.32$ & $25 b$ & $12,352.47$ & \\
\hline $8,035.35$ & $7 b$ & $12,441.59$ & \\
\hline $8,025.73$ & $3 b$ & $12,456.50$ & \\
\hline $8,025.42$ & $4 b$ & $12,456.98$ & \\
\hline $8,007.46$ & $3 b$ & $12,484.93$ & \\
\hline $7,970.25$ & $\begin{array}{r}3 b \\
10 b\end{array}$ & $\begin{array}{l}12,542.18 \\
12,543.21\end{array}$ & \\
\hline $7,952.46$ & $3 b$ & $12,571.27$ & \\
\hline 7, 943.91 & 500 & $12,584.80$ & \\
\hline 7, 932. 14 & 250 & $12,603.48$ & \\
\hline $7,918.37$ & 200 & $12,625.39$ & \\
\hline 7, 913. 49 & $10 b$ & $12,633.18$ & \\
\hline $7,912.55$ & $3 b$ & $12,634.68$ & \\
\hline $7,850.93$ & $2 h$ & $12,733.85$ & \\
\hline $7,801.30$ & $3 h$ & $12,814.86$ & \\
\hline $7,800.68$ & $4 h$ & $12,815.87$ & \\
\hline 7, 743. 84 & $4 h$ & $12,909.94$ & \\
\hline 7, 743. 14 & $4 h$ & $12,911.11$ & \\
\hline $7,680.48$ & $100 b$ & $13,016.44$ & \\
\hline $7,424.70$ & 20 & $13,464.86$ & $3 d^{3} \mathrm{D}_{3}^{\circ}-4 f^{3} \mathrm{~F}_{3}$ \\
\hline $7,423.64$ & 500 & $13,466.78$ & $3 d^{3} \mathrm{D}_{3}-4 f^{3} \mathrm{~F}_{4}$ \\
\hline $7,416.08^{a}$ & 250 & $13,480.50$ & $3 d^{3} \mathrm{D}_{2}-4 f^{3} \mathrm{~F}_{2}$ \\
\hline $7,409.14$ & 100 & $13,493.13$ & $3 d^{3} \mathrm{D}_{2}-4 f^{3} \mathrm{~F}_{3}$ \\
\hline $7,405.94$ & 300 & $13,498.96$ & $3 d^{3} \mathrm{D}_{1}-4 f^{3} \mathrm{~F}_{2}$ \\
\hline $7,289.28$ & 250 & $13,715.00$ & $3 d^{3} \mathrm{D}_{3}^{0}-4 f^{3} \mathrm{D}_{3}$ \\
\hline $7,275.24$ & 50 & $13,741.47$ & $3 d^{3} \mathrm{D}_{2}-4 f^{3} \mathrm{D}_{2}$ \\
\hline $7,250.74$ & $40 b$ & $13,788.09$ & $3 d^{3} \mathrm{D}_{3}-4 f \mathrm{X}_{3}$ \\
\hline 7, 235. 98 & $5 b$ & $13,816.03$ & $3 d^{3} \mathrm{D}_{2}^{\circ}-4 f \mathrm{X}_{3}$ \\
\hline $7,235.30$ & 10 & $13,817.32$ & $3 d^{3} \mathrm{D}_{2}-4 f^{3} \mathrm{D}_{1}$ \\
\hline $7,226.20$ & 10 & $13,834.73$ & $3 d^{3} \mathrm{D}_{1}^{\circ}-4 f^{3} \mathrm{D}_{1}$ \\
\hline 7, 208. 28 & $1 b$ & $13,869.12$ & $3 d^{3} \mathrm{D}_{3}-4 f \mathrm{X}_{2}$ \\
\hline $7,193.64$ & $6 b$ & $13,897.34$ & $3 d^{3} \mathrm{D}_{2}^{\circ}-4 f \mathrm{X}_{2}$ \\
\hline 7, 184. 94 & $7 b$ & $13,914.17$ & $3 d^{3} \mathrm{D}_{1}^{\circ}-4 f \mathrm{X}_{2}$ \\
\hline $7,167.47$ & $3 h$ & $13,948.08$ & \\
\hline $7,165.78$ & $50 h, l$ & $13,950.98$ & $3 d^{1} \mathrm{D}_{2}^{\circ}-5 f^{3} \mathrm{~F}_{3,2}$ \\
\hline $7,035.25$ & $50 b$ & $14,210.22$ & $3 d^{1} \mathrm{D}_{2}^{0}-5 f^{3} \mathrm{D}_{2}$ \\
\hline 7, 017. 81 & $10 h, l$ & $14,245.54$ & $3 d^{1} \mathrm{D}_{2}-5 f \mathrm{X}_{2}$ \\
\hline $7,005.73$ & $50 h, v$ & $14,270.11$ & \\
\hline $7,003.67$ & $50 h$ & $14,274.30$ & \\
\hline $6,976.80$ & $10 h$ & $14,329.27$ & \\
\hline $6,255.60$ & $3 h$ & $15,981.26$ & $3 d^{3} \mathrm{D}_{3}^{\circ}-5 f^{3} \mathrm{~F}_{3}$ \\
\hline $6,254.55$ & $15 h, l$ & $15,983.95$ & $3 d^{3} \mathrm{D}_{3}-5 f^{3} F_{4}$ \\
\hline $6,245.11$ & $2 h$ & $16,008.11$ & $3 d^{3} \mathrm{D}_{2}^{\circ}-5 f^{3} \mathrm{~F}_{2}$ \\
\hline 6, 244. 74 & $12 h$ & $16,009.06$ & $3 d^{3} \mathrm{D}_{2}^{\circ}-5 f^{3} \mathrm{~F}_{3}$ \\
\hline $6,238.42$ & $4 h$ & $16,025.27$ & $3 d^{3} \mathrm{D}_{1}-5 f^{3} \mathrm{~F}_{2}$ \\
\hline $6,156.00$ & $10 h$ & $16,239.83$ & $3 d^{3} \mathrm{D}_{3}-5 f^{3} \mathrm{D}_{2}$ \\
\hline $6,155.32$ & $50 h$ & $16,241.62$ & $3 d^{3} \mathrm{D}_{3}^{\circ}-5 f^{3} \mathrm{D}_{3}$ \\
\hline $6,145.22$ & $15 h$ & $16,268.32$ & $3 d^{3} \mathrm{D}_{2}^{\circ}-5 f^{3} \mathrm{D}_{2}$ \\
\hline
\end{tabular}

a This line appears to be complex on some plates, but is not sufficiently resolved to permit measurement of the components. 


\begin{tabular}{|c|c|c|c|}
\hline \multicolumn{1}{|c|}{$\lambda_{\text {air }} \mathrm{A}}$. & Intensity & $\nu_{\mathrm{VaO}} \mathrm{cm}^{-1}$ & Term combinations \\
\cline { 2 - 4 } $6,142.70$ & $6 h$ & $16,274.99$ & $3 d^{3} \mathrm{D}_{3}^{\circ}-5 f \mathrm{X}_{2}$ \\
$6,132.14$ & $4 h$ & $16,303.02$ & $3 d^{3} \mathrm{D}_{2}^{\circ}-5 f \mathrm{X}_{2}$ \\
$6,131.60$ & $5 h$ & $16,304.45$ & $3 d^{3} \mathrm{D}_{2}^{\circ}-5 f^{3} \mathrm{D}_{1}$ \\
$6,125.44$ & $2 h$ & $16,320.85$ & $3 d^{3} \mathrm{D}_{1}^{\mathrm{i}}-5 f \mathrm{X}_{2}$ \\
$6,124.85$ & $5 h, l$ & $16,322.42$ & $3 d^{3} \mathrm{D}_{1}^{\circ}-5 f^{3} \mathrm{D}_{1}$ \\
$5,948.584$ & 100 & $16,806.08$ & $4 s^{1} \mathrm{P}_{1}^{\circ}-5 p^{1} \mathrm{D}_{2}$ \\
$5,797.912$ & 40 & $17,242.82$ & $4 s^{3} \mathrm{P}_{2}^{\circ}-5 p^{3} \mathrm{D}_{3}$ \\
$5,793.128$ & 30 & $17,257.06$ & $4 s^{3} \mathrm{P}_{1}^{\circ}-5 p^{3} \mathrm{D}_{2}$ \\
$5,780.452$ & 25 & $17,294.90$ & $4 s^{1} \mathrm{P}_{1}^{\circ}-5 p^{1} \mathrm{~S}_{0}$ \\
$5,772.258$ & 50 & $17,319.45$ & $4 s^{3} \mathrm{P}_{0}^{\circ}-5 p^{3} \mathrm{D}_{1}$ \\
$5,754.258$ & $8 b$ & $17,373.63$ & $4 s^{3} \mathrm{P}_{2}^{\circ}-5 p^{3} \mathrm{P}_{1}$ \\
$5,708.437$ & 75 & $17,513.08$ & $4 s^{3} \mathrm{P}_{2}^{\circ}-5 p^{3} \mathrm{P}_{2}$ \\
$5,701.138$ & 25 & $17,535.50$ & $4 s^{3} \mathrm{P}_{1}^{\circ}-5 p^{3} \mathrm{P}_{0}$ \\
$5,690.470$ & 40 & $17,568.38$ & $4 s^{3} \mathrm{P}_{1}^{\circ}-5 p^{3} \mathrm{P}_{1}$ \\
$5,684.523$ & 50 & $17,586.76$ & $4 s^{3} \mathrm{P}_{2}^{\circ}-5 p^{3} \mathrm{~S}_{1}$ \\
$5,665.601$ & 25 & $17,645.49$ & $4 s^{3} \mathrm{P}_{0}^{\circ}-5 p^{3} \mathrm{P}_{1}$ \\
$5,645.665$ & 25 & $17,707.80$ & $4 s^{3} \mathrm{P}_{1}^{\circ}-5 p^{3} \mathrm{P}_{2}$ \\
$5,622.22$ & 3 & $17,781.64$ & $4 s^{3} \mathrm{P}_{1}^{\circ}-5 p^{3} \mathrm{~S}_{1}$ \\
$4,102.926$ & 25 & $24,366.00$ & $3 p^{1} \mathrm{~S}_{0}-4 s^{3} \mathrm{P}_{1}^{\circ}$ \\
$3,905.527$ & 100 & $25,597.52$ & $3 p^{1} \mathrm{~S}_{0}-4 s^{1} \mathrm{P}_{1}^{\circ}$ \\
& & & \\
\hline
\end{tabular}

The classified lines of table 1 arise from combinations of new terms with those of Fowler's $4 s, 6 s, 5 p$, and $3 p^{\prime}$ groups. In table 2, which is abstracted from a similar table given by Fowler, are set forth the terms to be expected theoretically for the various electron configurations of the neutral silicon atom. Concerning the terms of the $4 p$ group, he states that "the principal combinations . . . are outside the range of the observations in the infrared." These have now been established by the group of strong infrared lines between 10,000 and $11,000 \mathrm{~A}$, representing the transition $4 p \rightarrow 4 s$. Only the terms $4 p^{1} \mathrm{P}_{1}, 4 p^{3} \mathrm{D}_{1}$, and $4 p^{3} \mathrm{P}_{0}$ are uncertain, the others being verified through intersystem combinations or combinations with terms from the $n s$ configurations.

TABLE 2.-Theoretical terms of Si I

\begin{tabular}{|c|c|}
\hline $\begin{array}{l}\text { Electron con- } \\
\text { figuration }\end{array}$ & $\begin{array}{c}\text { Terms of Si I with }{ }^{2} \mathrm{P}^{\circ} \text { of Si II as } \\
\text { limit }\end{array}$ \\
\hline $\begin{array}{l}3 s^{2} \cdot 3 p^{2} \\
3 s^{2} .3 p . n s \\
3 s^{2} .3 p . n p \\
3 s^{2} .3 p . n d \\
3 s^{2} .3 p . n f \\
3 s .3 p^{3}\end{array}$ & 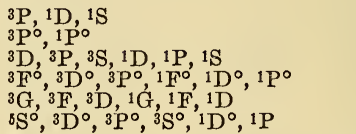 \\
\hline
\end{tabular}

The ${ }^{3} \mathrm{D}^{\circ}$ and ${ }^{1} \mathrm{D}^{\circ}$ terms, which Fowler assigns to the $s p^{3}$ configuration, are involved in the production of some of the groups of diffuse lines that appear between 6,100 and 9,000 A. Many of the intense lines of these groups are separated by nearly the same wave-number differences as occur between the components of the ${ }^{3} \mathrm{D}^{\circ}$ term. The observations with the high dispersion spectrographs have shown that in reality these strong silicon lines are attended by much fainter, close satellites, thus indicating that the higher terms involved in their production have very narrow separations and arise from an $s^{2} p f$ configuration. This view is supported by the fact that the new 
terms are hydrogen-like in character, being closely represented by a Rydberg formula, as shown below. This suggests that the ${ }^{3} \mathrm{D}^{\circ}$ and ${ }^{1} \mathrm{D}^{\circ}$ terms owe their origin to the $3 d$ electron, a possibility recognized by Fowler, who states, ". . . the $3 p^{\prime}$ and $3 d$ terms yield similar combinations with the deep $3 p$ terms, so that the $3 p^{\prime}$ terms might have been called $3 d$, and subsequent $d$ terms $4 d$ and $5 d$." The $3 d$ configuration requires a ${ }^{3} \mathrm{~F}^{\circ}$ term in addition to ${ }^{3} \mathrm{D}^{\circ},{ }^{3} \mathrm{P}^{\circ}$, and the corresponding singlet terms. Fowler's analysis of Si I does not give this term, although it should have a value of approximately 17,000 on his term scale. The parallel group of terms in Ge I has been assigned to the $4 d$ electron by Rao ${ }^{10}$ who has established the ${ }^{3} \mathrm{~F}^{\circ}$ term through its combination with the ground term $4 p^{3} \mathrm{P}$. Corresponding lines of Si $\mathrm{r}$ have not been found, although the ultraviolet from 1,950 A to 3,000 A has been resurveyed with the grating and Hilger E 1 spectrographs of the Bureau of Standards. Further attempts to establish the ${ }^{3} \mathrm{~F}^{\circ}$ term through its combinations with terms of the $n f$ configurations have also proved unsuccessful, although it is probable that the strong, unclassified lines at 7,918, 7,932, and 7,943 A may represent its combination with $4 f^{3} \mathrm{G}$.

Fowler gives three terms, ${ }^{3} \mathrm{D}$ ?, ${ }^{3} \mathrm{P}$ and ${ }^{1} \mathrm{~S}$ of the $5 p$ configuration, of which ${ }^{3} \mathrm{P}$ is verified in this investigation, through its combinations with $3 d^{3} \mathrm{D}^{\circ}$ and $3 d^{1} \mathrm{D}^{\circ}$. It has not been possible to verify ${ }^{3} \mathrm{D}$ ?, in a similar manner. Prolonged exposures made with the large grating spectrographs and intended to bring out the satellite lines of its combination with $4 s^{3} \mathrm{P}^{\circ}$ likewise failed to verify the $5 p{ }^{3} \mathrm{D}$ term. However, the term fits satisfactorily into a Rydberg formula with $4 p{ }^{3} \mathrm{D}$ so that Fowler's estimate of it is very probably correct. It is of interest to note that faint, unidentified solar lines agree in wave length with the required satellite lines.

From the arrangement of the singlet terms in the $4 p$ configuration, we may infer a similar arrangement for the corresponding singlet terms of the $5 p$ configuration. This suggests that Fowler's term $5 p{ }^{1} \mathrm{~S}_{0}$ is in reality $5 p^{1} \mathrm{D}_{2}$. The unclassified yellow line at $5780.4 \mathrm{~A}$ may then be interpreted as the combination $4 s^{1} \mathrm{P}_{1}-5 p{ }^{1} \mathrm{~S}_{0}$ giving the value 7478.3 for the ${ }^{1} \mathrm{~S}$ term. Although these terms are not verified through combinations with the $3 d$ terms, yet evidence in support of their reality is furnished by the fact that they form Rydberg sequences with the $4 p$ terms as shown in table 4 . It has not been possible to establish the term $5 p{ }^{1} \mathrm{P}_{1}$.

On one of the strong grating exposures there appears a faint line at wave length $5,622.22 \AA$, which is separated by $194.81 \mathrm{~cm}^{-1}$ from the unclassified silicon line at 5,684.52 A. This pair of lines may be interpreted as $4 s^{3} \mathrm{P}_{2}^{0}, 1-5 p{ }^{3} \mathrm{~S}_{1}$, but no combinations of the new term, $5 p{ }^{3} \mathrm{~S}$, with other terms have been found to verify it. It is of interest, however, to note that a faint unidentified line appears in the solar spectrum at 5,622.237 A, which lends support to the view that the new line is related to the other yellow silicon lines, all of which are present in the sun's spectrum.

The new terms for Si I are given in table 3, which also gives corrections to some of Fowler's terms. The values of the terms are based on Fowler's scale, which is quite accurately determined, although some of his series now require revision. The designations of the new

10 Proc. Roy. Soc. (London), A 124, p. 465, 1929. 
terms of the $n f$ configurations have been determined from their combinations with the $3 d$ terms and from consideration of their behavior in forming series. Table 4 shows the effective quantum numbers or Rydberg denominators of the new terms. All the series are satisfactorily represented by the Rydberg formula with the exception of the $n f{ }^{3} \mathrm{~F}_{4}$ terms, which, however, would satisfy the formula if their limit were ${ }^{2} \mathrm{P}_{1 / 2}$ instead of ${ }^{2} \mathrm{P}_{3 / 2}$ of $\mathrm{Si}$ II. In this case, the effective quantum numbers would be 3.9658 and 4.9604 , respectively.

TABLE 3.-New and revised terms of Si I

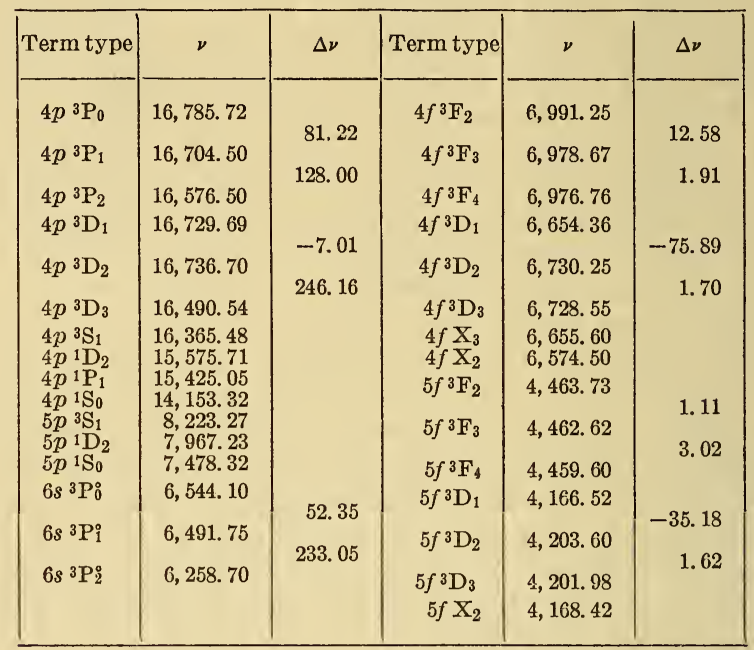

TABLE 4.-Rydberg denominators

\begin{tabular}{|c|c|c|c|c|c|c|c|c|c|}
\hline Terms & ${ }^{3} \mathrm{~S}_{1}$ & ${ }^{3} \mathrm{P}_{0}$ & ${ }^{3} \mathrm{P}_{1}$ & ${ }^{3} \mathrm{P}_{2}$ & ${ }^{3} \mathrm{D}_{1}$ & ${ }^{3} \mathrm{D}_{2}$ & ${ }^{3} \mathrm{D}_{3}$ & ${ }^{1} \mathrm{~S}_{0}$ & ${ }^{1} D_{2}$ \\
\hline $\begin{array}{l}3 p \\
4 p \\
5 p\end{array}$ & $\begin{array}{l}\text { 2. } 5670 \\
\text { 3. } 5908\end{array}$ & $\begin{array}{l}1.2917 \\
2.5568 \\
3.5996\end{array}$ & $\begin{array}{l}1.2925 \\
2.5630 \\
3.6066\end{array}$ & $\begin{array}{l}1.2911 \\
2.5510 \\
3.5754\end{array}$ & $\begin{array}{l}\text { 2. } 5610 \\
\text { 3. } 5390\end{array}$ & $\begin{array}{l}2.5605 \\
3.5417\end{array}$ & $\begin{array}{l}2.5575 \\
3.5789\end{array}$ & $\begin{array}{l}1.4718 \\
2.7566 \\
3.7592\end{array}$ & $\begin{array}{l}\text { 1. } 3552 \\
\text { 2. } 6301 \\
\text { 3. } 6462\end{array}$ \\
\hline
\end{tabular}

\begin{tabular}{|c|c|c|c|c|c|c|c|}
\hline Terms & ${ }^{3} \mathrm{D}_{1}$ & ${ }^{3} \mathrm{D}_{2}$ & ${ }^{3} \mathrm{D}_{3}$ & ${ }^{3} \mathrm{~F}_{2}$ & ${ }^{3} \mathrm{~F}_{3}$ & ${ }^{3} \mathrm{~F}_{4}$ & $\mathrm{X}_{2}$ \\
\hline $\begin{array}{l}4 f \\
5 f\end{array}$ & $\begin{array}{l}3.9760 \\
4.9629\end{array}$ & $\begin{array}{l}3.9547 \\
4.9440\end{array}$ & $\begin{array}{l}3.9547 \\
4.9440\end{array}$ & $\begin{array}{c}3.9618 \\
4.9581\end{array}$ & $\begin{array}{c}3.9652 \\
4.9591\end{array}$ & $\begin{array}{c}3.8866 \\
4.8078\end{array}$ & $\begin{array}{l}3.9902 \\
4.9627\end{array}$ \\
\hline
\end{tabular}

It remains to direct attention to some of the groups of unclassified silicon lines. The probable origin of the strong lines 7,918, 7,932, and 7,943 $\mathrm{A}$ was mentioned above. There are two other groups of diffuse lines which are apparently related through a common term involving the separations 106.5 and $81.1 \mathrm{~cm}^{-1}$. The strongest lines of these groups are at 7,680.48 $\mathrm{A}$ and 8,648.54 $\mathrm{A}$. Both appear as absorption lines in the sun's spectrum, although the former as a solar line, is much too strong to be due solely to manganese to which it is ascribed. In conclusion it may be pointed out that much yet remains to be found out about Si I, but that progress will most likely be made with a source different from the arc in air.

Washington, August 16, 1933. 